\title{
ANALYSIS OF TOURIST FLOW FROM THE US TO TAIWAN
}

\author{
Yen-Hsun CHEN ${ }^{1}$ - Hsin-Hong $\mathrm{KANG}^{2}$ \\ ${ }^{1}$ Department of Business Administration, National Cheng Kung University, No. 1, University \\ Road, Tainan City 701, Taiwan, R.O.C. \\ Department of Leisure and Sports Management, Far East University, No. 49, Zhonghua Rd., \\ Xinshi Dist., Tainan City 74448, Taiwan, R.O.C. \\ E-mail:yhchen@cc.feu.edu.tw (corresponding author) \\ ${ }^{2}$ Department of Business Administration, National Cheng Kung University, No. 1, University \\ Road, Tainan City 701, Taiwan, R.O.C.E-mail: hhkang@mail.ncku.edu.tw
}

\begin{abstract}
It is important for Taiwanese policy makers to understand how economic factors affect US tourists' decision to travel to Taiwan. For the long-run analysis, Johansen's cointegration test reveals that three cointegration vectors exist among the model variables, indicating a long-run relationship. To conduct a short-run analysis, this paper employs vector auto regression (VAR) to estimate the responses of US tourists in Taiwan to the shocks of changes to personal disposable income, cost of living, and substitute price. The short-run equilibrium adjustment processes are discussed in terms of generalized impulse response. The results show an immediate and significant response of changes in tourist arrivals to their own impacts, changes in the cost of living, and changes in the substitute price. In addition, the price, income, and cross-elasticity of tourism demand are all positive at the beginning of the responses, implying that the tourism products can be attributed to normal and substitute goods.
\end{abstract}

Keywords: tourist flow, VAR, generalized impulse response, Taiwan

\section{INTRODUCTION}

Over the decades, rapid growth, continued expansion, and diversification have opened up the global tourism industry. Consequently, tourism is now regarded as one of the largest economic sectors in the world (Katircioglu 2009). Many new destinations have emerged besides the traditional favourites in Europe and North America. No matter what you intend to experience, you should be able to find many suitable destinations. Indeed, international tourist arrivals have reached unprecedented levels, from 278 million in 1980, to 528 million in 1995, to 1.035 billion in 2012. Furthermore, the 2013 UNWTO Tourism Highlights proposed 
that international tourist arrivals worldwide would increase by $3.3 \%$ per year from 2010 to 2030 , to reach 1.8 billion by 2030 . The result is nearly conclusive that more arrivals will bring in more tourist spending, as an alternative form of exports, contributing to the balance of payments through foreign exchange earnings and representing a significant income source for a national economy (Balaguer and Cantavella-Jorda 2002; Chang 2014). Fundamentally, the growth of international tourism receipts matches the growth in arrivals, rising from $\$ 262$ billion in 1990 to $\$ 1.075$ trillion in 2012 . There is no doubt that tourism will be a booming industry. In addition, after long-term tourism development, global consumer trends indicate that most tourists are becoming more discerning in their choice of destinations, and thus less predictable and more spontaneous in terms of their consumption patterns (Burger et al. 2001). Therefore, analysing tourism demand in depth is an essential task on which all tourism-related business decisions ultimately rely.

The destination country in focus, Taiwan, is an island nation located to the southeast of China, across the Taiwan straits, with Japan and Korea as its neighbours to the north and the Philippines to the south. In short, Taiwan is practically located at the centre of Asia, and it occupies a significant geographic and commercial position in the continent. By following a traditional island economic model, the last five decades have been characterized by sharp economic growth principally due to substantial exports (Ghartey 1993), and dramatic growth in the Taiwanese gross domestic product (GDP) appeared over 260 times from 1961 to 2011 (Financial database of the Taiwan Economic Journal). Recently, especially in the last decade, due to immense international competition, principally in the manufacturing sector, manufacturing exports alone have not been able to sustain Taiwan's economic growth. To stimulate the impotent economy, Taiwan must aggressively and unremittingly carry out an industrial transformation, such as raising the output value of the service industry, like tourism. In order to boost the output of the tourism industry, the Taiwanese government has carried out many actions in the past ten years, such as the recent 'Tour Taiwan Years 20082009: Great Quarterly Tourist Giveaway Program', 'The Best Trip in the World - Taiwan Explorers Wanted' contest, 'Medium-term Plan for the Construction of Major Tourist Sites (2008-2015)', 'Project Vanguard for Excellence in Tourism (2009-2014)', and so on. After these initiatives were undertaken, the number of annual inbound visitors to Taiwan in 2013 had increased by $9.64 \%$ annually, reaching a record high of $8,016,280$,which was about 26 times the number of tourists in 1968 (Taiwan Tourism Bureau).

In the past, many of the international tourists to Taiwan were from Japan, Hong Kong, the US, Singapore, South Korea, and Thailand. However, until 2010, those from mainland China far exceeded all other tourists, due to Taiwan's openness to 
Chinese tourists, who came to occupy an increasingly important position in the Taiwanese tourism industry. Several authors have conducted empirical studies on the correlation between tourism demand and the economic conditions of Taiwan. For example, Kim, Chen, and Jang (2006), Lee and Chien (2008), and Chen and Song Zan (2009) used overall tourist arrivals as a proxy for tourism growth to discuss the relationship between tourism development and macroeconomic growth. Nevertheless, researchers have largely overlooked the tourism arrival changes from individual origin counties in response to different macroeconomic conditions. In this paper, an individual origin country will be chosen to determine the relationship between its tourism demand and economy, which could be effectively in favour of more detailed policy making. However, which country is more interested in this? Mainland China seems like the obvious answer, given the historical openness to Chinese tourists, but the datasets to support this are lacking. Another distinct and valuable country of origin to research is the United States. Although it does not have the close geographical relationship to Taiwan that the other abovementioned countries do, the US has nevertheless been a main source of tourists to Taiwan for decades, likely due to the long established, very friendly, and strong ties between the two countries, despite economic, cultural, military, political, or educational affairs. Since the US is distinct from the other tourist source countries, its relationship with the Taiwanese tourism industry is the focus of this research.

This paper aims to investigate the relationship between international tourist arrivals from the US to Taiwan and the three economic variables of US personal disposable income (PDI), tourist cost of living, and substitute price. Before verifying the relationship and impact, we must first check whether the four variables are stationary. Unit root tests revealed the existence of unit roots in the two time series of US PDI and substitute price, the degree of integration I(1), whereas tourist arrivals from the US to Taiwan and cost of living were tested as I(0). Further tests indicated that all four first-differenced variables are stationary. In general, as an I(1) series found, either a vector auto regression (VAR) model (Oh 2005; Song and Witt 2006) with first differences or a vector error correction model (VECM) (Gunes 2007) could be used. However, Engle and Yoo (1987) and Hoffman and Rasche (1996) showed that the performance of an unrestricted VAR is superior to a restricted VECM at short horizons. Hence, the unrestricted VAR is adopted with the first-differenced data in this paper. The short-run equilibrium adjustment processes are also discussed in terms of a generalized impulse response analysis (Su 2014). We found that the response of the tourist arrival change is immediately and significantly positive to its own impacts and the changes in substitute prices, whereas a negative sign at the beginning appears with the change of the cost of living. Therefore, on the basis of the results in this paper, it could be inferred that 
the price elasticity, income elasticity, and cross-elasticity for tourism demand are all greater than zero, implying that the tourism products are attributed to normal and substitute goods.

The remainder of the paper is organized as follows. Section 2 presents a literature review describing the recent publications concerning tourism economies; this will provide the rationale for the selections of the research topic and methodology. Section 3 describes the tendency and the seasonality of the tourist arrivals from the US. Section 4 describes the model, data, and results, and the final section presents the conclusions.

\section{LITERATURE REVIEW}

A search of the existing literature reveals that very few papers have been published in international academic journals concerning Taiwan's tourism industry. One of the reasons for this is that Taiwan has not been regarded as a traditional and famous destination, perhaps due to low awareness of Taiwan's tourist attractions among international tourists. For example, many Americans and Europeans cannot accurately indicate where Taiwan is, let alone select Taiwan as a holiday destination. The first paper concerning the relationship between tourism and Taiwan's economy was that of Kim, Chen, and Jang (2006). Their paper examined the causal relationship between tourism expansion and economic development in Taiwan by tourist arrivals and GDP variables, and they found a long-run equilibrium relationship and bi-directional causality (Ahmed and Kwan 1991) between the two factors; thus, they determined that tourism and economic development reinforce each other. While the published papers about Taiwanese tourism demand just discussed overall aspect of tourist arrivals, they have not done so in the context of detailed research about an individual origin country.

Dritsakis (2004) investigated changes in the long-run demand in Germany and Great Britain for tourism to Greece, using several leading macroeconomic variables, including income in the origin countries, tourism prices in Greece, and transportation costs and exchange rates among the three countries. In the same years, Lim (2004) analyzed the seasonal patterns of tourist arrivals from South Korea to Australia, using econometric time series modelling to quantify the factors affecting the flow of international tourists between Australia and South Korea. Song and Witt (2006) used VAR to forecast tourist flows to Macau from eight major origin countries, suggesting that Macau will face increasing tourism demand from mainland China. Nevertheless, the tourist arrivals to Taiwan from major origin countries have yet to be the focal point of such discussions in academic papers. In this paper, given the importance of the US as an origin country, 
the relationship between Taiwan's tourist arrivals from the US and certain factors is analyzed.

Much of the evidence in the tourism research suggests that some characteristics of the demand and thus of the origin, like income, exchange rate, prices, and population density, clearly affect the general propensity for outbound tourism flows. Sometimes other supply factors, like cultural attractions, historical sites, natural elements, recreational facilities, and amenities, are relevant in influencing tourism arrivals. In general, the more significant determinants affecting origindestination tourist flows are mostly economic factors, because economies obviously vary over data time spans (Djeri et al. 2014). The other factors are ordinary fit to the panel analyses of multinational and domestic tourism demands due to the substantial diversity of geographic, cultural, or recreational aspects. Hence, some economic factors were adopted in this research for analysing the tourism demand of US tourists. Subject to research effectiveness, it is important to verify which economic factors should affect tourism demand.

Income in the country of origin is one of the most important economic determinants for explaining tourist flows, since it measures how consumers demand for travel reacts to a change in the consumers wealth (Marrocu and Paci 2013). Lim (1997) argued that discretionary income should be used as the appropriate measure of income in the demand model. This is an adequate proxy variable, but the data cannot be easily obtained in practice. Therefore, alternative income measures have to be used as a proxy for tourists' discretionary income. Among these alternatives, such as GDP, gross national product (GNP), PDI, and gross national income (GNI), real PDI is the best proxy to include in the demand models relating to holidays or travel to visit friends and relatives (Kulendran and Witt 2001; Song et al. 2000; Song and Witt 2006). Therefore, the monthly data of real PDI is chosen as one of the economic factors in this paper.

As regards price considerations, international travellers intuitively use the familiar economic data of exchange rates. If a destination's currency depreciates, international tourists will feel that the trip will be cheap and worth the journey; consequently, the tourist flow should increase. Another common variable relating to the perception of tourists' living costs is the customer price index (CPI), which shows how tourists' expenditure would have to move to compensate for price changes, so as to allow tourists to maintain the unintended tourism quality. However, the previous literature is almost unanimous in taking into account both exchange rate and CPI, whether by sole representation or a composite measure of effective price adjusted by the exchange rate in the tourism demand equation.

Recently, the relative price issue has been combined in discussions of tourism own price. Song and Witt (2006) pointed out that own price should contain two components in theory: the cost of living at the destination and the transportation 
cost to reach the destination. However, due to data availability, transportation cost was omitted in many studies; similarly, this paper will not consider transportation costs. The cost of living was examined by Qiu and Zhang (1995), who used the exchange rate between the destination and origin countries as well as a separate CPI variable to account for the cost of tourism. Further, the majority of the published studies, especially the most recent ones, such as that of Song and Witt (2006), employed an exchange rate adjusted relative price index between the destination country and country of origin as the tourism effective price variable. In this paper, the exchange rate adjusted relative price index is calculated for the variable of cost of living.

In addition to own price, Kim and Song (1998), Song et al. (2000), Song and Witt (2003), and Song and Witt (2006) showed that substitute prices in competitive destinations are important determinants. There are two kinds of substitute prices: one allows for the substitution between the destination and a competitive destination, and the other calculates the cost of tourism in the destination under consideration relative to a weighted average cost of living in various competing destinations, and this index is also adjusted by relevant exchange rates. The weight is the relative market share of each competing destination (Song and Witt 2003). In this study, the first form is adopted by setting a hot destination, Hong Kong, as the single competing destination, because the market share ratios of major competing countries are difficult to obtain. In addition, Hong Kong is situated near Taiwan, and has similar tourism and business models to those of Taiwan.

\section{INTERNATIONAL TOURIST ARRIVALS FROM THE US TO TAIWAN}

Tourist arrivals from the US have become a stable source of Taiwan's inbound tourist market, increasing by about 16\% between 2001 and 2013. However, compared to Japan or Hong Kong, the growth rate of the tourist arrivals from the US to Taiwan has been small and with no obvious time tendency, as shown in Figure 1. In addition, US tourist arrivals in this paper are verified as a stationary series by unit root tests, which means that the mean and variance of this series are almost constant overtime and the auto covariance is not time varying. Thus, it is not easy to break this inertia and then increase the US arrivals up by a wide margin, if no new promotions or policies are implemented. Therefore, the US tourism demand must be examined in greater detail in short-run analyses for adjusting immediately suitable strategies for tourism agents or governments. In Figure 1, an abrupt shrink is very obvious in 2003, caused by the Severe Acute Respiratory Syndrome (SARS) epidemic. 


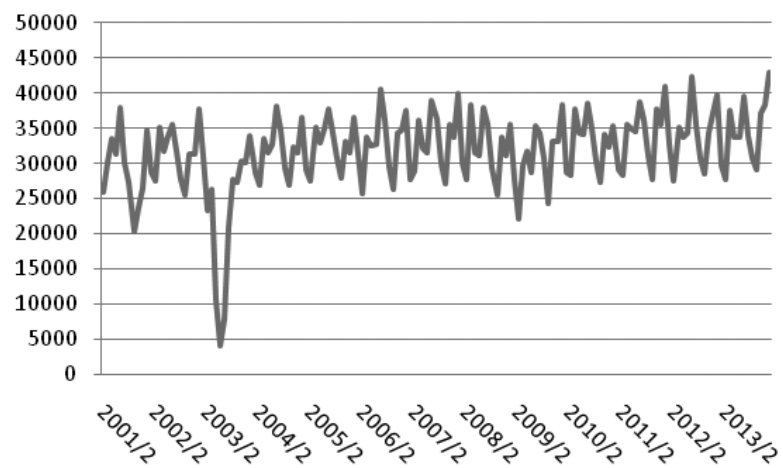

Figure 1. Monthly tourist arrivals from the US

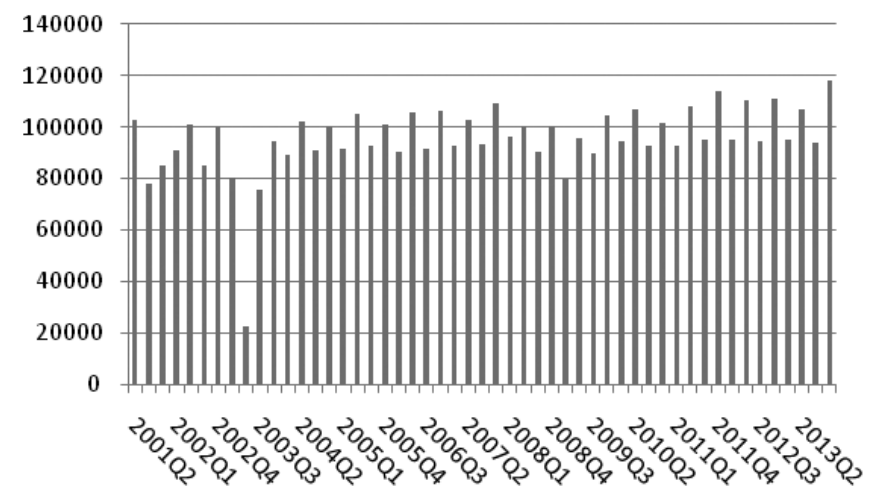

Figure 2. Quarterly tourist arrivals from the US

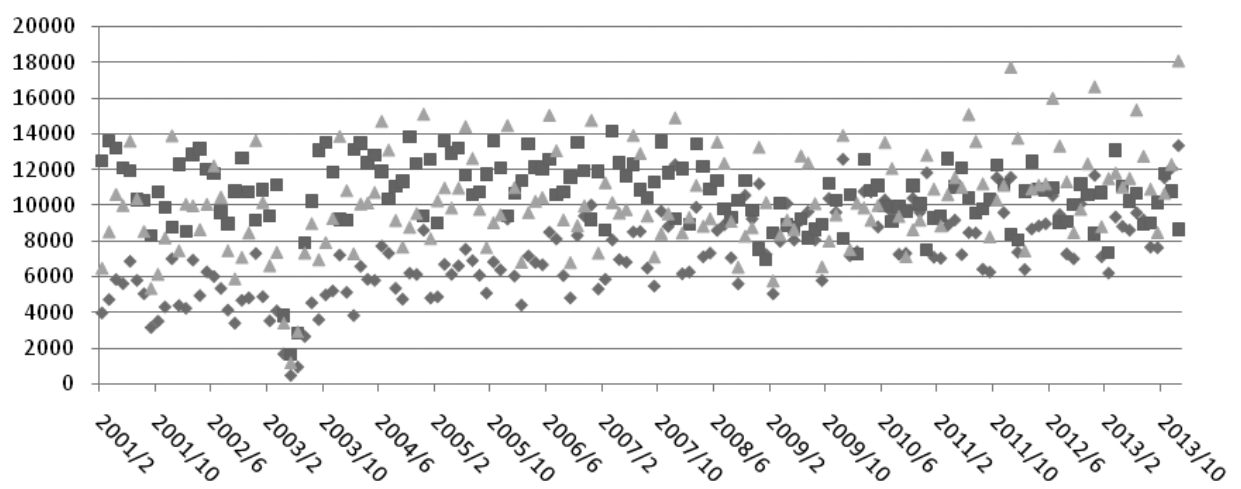

Figure 3. Monthly tourist arrivals from the US by purpose 
The seasonal patterns of tourist arrivals from the US to Taiwan will now be discussed. The quarterly data shown in Figure 2 seems to suggest that tourist arrivals from the US to Taiwan display strong seasonal patterns. Monthly seasonal indices for tourist arrivals are computed to support this observation of seasonality by using the ratio-to-moving average technique, calculated with the seasonally unadjusted monthly data of tourist arrivals from March 2001 to December 2013, as follows (Lim and McAleer 2001):

$$
P_{t}=\frac{A_{t}}{M A_{t}} \times 100 \%
$$

where $P_{t}$ is the ratio-to-moving average, $A_{t}$ is the tourist arrivals in levels, and $\mathrm{MA}_{t}$ is the moving average. This procedure is intended to eliminate the trend and cyclical components, thereby resulting in a series that contains seasonal movements. During the period, March, June, July, October, November, and December were the high seasons for inbound US tourists. In the important US holiday month of December, the fact that more Americans come to Taiwan to enjoy their vacations, and many Taiwanese Americans return to Taiwan to visit their relatives and friends (shown in Figure 3), makes December Taiwan's peak tourist season. Since tourist arrivals, especially for the purposes of sightseeing and visiting relatives, decrease as summer vacation ends (shown in Figure 3), September becomes the least popular month, as shown in Table 1.

Table 1. Seasonal indices for tourist arrivals from the US

\begin{tabular}{ll}
\hline Month & Seasonal indices \\
\hline January & 0.960 \\
\hline February & 0.869 \\
\hline March & 1.109 \\
\hline April & 0.969 \\
\hline May & 0.937 \\
\hline June & 1.096 \\
\hline July & 1.067 \\
\hline August & 0.959 \\
\hline September & 0.802 \\
\hline October & 1.070 \\
\hline November & 1.039 \\
\hline December & 1.222 \\
\hline
\end{tabular}




\section{THE MODEL, DATASET AND RESULTS}

\subsection{Introduction}

This paper is attempting to understand the relationship between the variable of international tourist arrivals from the US to Taiwan and the three economic variables of US PDI, tourist cost of living, and substitute price. Before verifying the relationship and impact, we must first check whether the four variables are stationary. The next subsection concerning the unit root tests reports that there exist unit roots in the two time series of US PDI and substitute price, denoted byte degree of integration I(1), whereas tourist arrivals and cost of living are checked as I(0). Testing further, all four first-differenced model variables are stationary. However, if an I(1) process is found, it involves estimation of the VAR model with first differences, otherwise a VECM is estimated if cointegration exists. Naka and Tufte (1997) argued that an unrestricted VAR performs better than a VECM. Moreover, Engle and Yoo (1987) and Hoffman and Rasche (1996) proposed that an unrestricted VAR is superior to a restricted VECM at short horizons. Therefore, the unrestricted VAR is adopted in this study with the use of first-differenced data. Finally, the short-run equilibrium adjustment processes are discussed with the generalized impulse response analysis.

The monthly data over the period of March 2001 through December 2013 is estimated in this paper. The model variables are the tourists arriving from the US, the US PDI is the own price, and the substitute price. The cost of living is deemed as the index variable of own price in Taiwan, normally measured by Taiwanese CPI divided by US CPI and adjusted by the appropriate exchange rate. The substitute price is measured by the relative CPI of Hong Kong to Taiwan adjusted by the appropriate exchange rate, because Hong Kong is generally regarded as Taiwan's main opponent in the tourism industry. The data pertaining to tourist arrivals from the US was obtained from Tourism Bureau, Ministry of Transportation and Communications, Republic of China (Taiwan); that regarding PDI was obtained from the financial database of Taiwan Economic Journal; and the cost of living and the substitute price were calculated using the exchange rates and CPI of Taiwan, the US, and Hong Kong provided in Taiwan Economic Journal. Subsequently, the four model variables were transformed by the use of natural logarithms to ease the interpretation of coefficients. In addition, since there is a concern of removing important information while adjusting for seasonality, unadjusted data are used. 


\subsection{Unit root for the order of integration}

The Augmented Dickey-Fuller (ADF) and Phillips-Perron (PP) tests are used to determine whether a time series variable is non-stationary or stationary. All procedures allow for fitted drift in the time series model. The ADF test accounts for temporally dependent and heterogeneously distributed errors by including lagged innovation sequences in the fitted regression. In contrast, the PP procedure accounts for non-independent and identically distributed (n.i.i.d.) processes using a nonparametric adjustment to the standard Dickey-Fuller (DF) procedure. The results of testing the order of the variables of tourist arrivals from the US (USTA), US PDI (USPDI), cost of living (USCL), and substitute price (USSP) are shown in Table 2. The tests strongly support the null hypothesis of non-stationary for the level variables of USPDI and USSP, but reject those for the level variables of USTA and USCL. Then, the first-differenced series of all four model variables are stationary because the null hypotheses were rejected at the $1 \%$ significance level. In short, USTA and USCL significantly belong to the zero order of integration I(0), whereas USPDI and USSP belong to I(1).

The unit root test shows that there exist different orders of integration, $\mathrm{I}(0)$ and I(1), for the four model variables. In other words, we cannot use the approach of conventional regression and unrestricted VAR. When we study a non-stationary time series, the regression usually produces significant ordinary least squares (OLS) parameter estimates, yet the residuals are ordinarily non-stationary, thus violating the standard assumption of classical econometrics. This problem is known as spurious regression, and a VAR model may also encounter the same problem. In addition, Toda and Yamamoto (1995) noted that conventional asymptotic theory is, in general, not applicable to hypothesis testing in levels VARs if the variables are integrated, I(1). Therefore, following Naka and Tufte's (1997) argument, an unrestricted VAR is adopted with the use of first-differenced data for short-run analysis in this paper.

Table 2. Results of unit root tests

\begin{tabular}{lcccccccc}
\hline Variables & \multicolumn{2}{c}{ USTA } & \multicolumn{2}{c}{ USPDI } & \multicolumn{2}{c}{ USCL } & \multicolumn{2}{c}{ USSP } \\
\hline Test method & ADF & PP & ADP & PP & ADF & PP & ADF & PP \\
\hline \multirow{2}{*}{ Level } & $-3.77^{* * *}$ & $-6.8^{* * *}$ & -2.46 & -1.88 & $-3.63^{* *}$ & $-3.81^{*}$ & -2.82 & -2.45 \\
& $(0.0004)$ & $(0.00)$ & $(0.3497)$ & $(0.6617)$ & $(0.0304)$ & $(0.0185)$ & $(0.0581)$ & $(0.1301)$ \\
\hline First- & $-9.68^{* * *}$ & $-16.59^{* * *}$ & $-12.72^{* * *}$ & $-12.71^{* * *}$ & $-10.38^{* * *}$ & $-10.37^{* * *}$ & $-9.12^{* * *}$ & $-10.7^{* * *}$ \\
differenced & $(0.00)$ & $(0.00)$ & $(0.00)$ & $(0.00)$ & $(0.00)$ & $(0.00)$ & $(0.00)$ & $(0.00)$ \\
\hline
\end{tabular}

Notes: The optimal lag length determined using Akaike's Information Criterion (AIC). Numbers without ( ) are the t-statistics for each kind of unit root test. Numbers in parentheses ( ) are probabilities, p-values. To reject the null hypothesis of having a unit root at different significance levels $1 \%, 5 \%$, or $10 \%$, this means that a time series is stationary. $* * *$ indicates the t-statistics at the $1 \%$ significance level; similarly, $* *$ and $*$ indicate the $5 \%$ and $10 \%$ significance levels, respectively. 


\subsection{Vector auto regression}

Since the dependent variable, tourist arrivals, and the other three economic variables do not have the same order of integration, the Johansen cointegration test (Brida et al. 2010) is performed. Further, trace or maximum eigenvalue tests both show that three cointegration vectors exist among the four model variables at the $95 \%$ level, identifying long-run relationship between the variables in the long-run model. Hence, for the short run, the unrestricted VAR of the first-differenced data is suitable for generating a tourism demand model.

International tourism flows are subject to disruption by a range of events that may occur in a destination itself, in a competing destination, origin markets, or even in remote areas. In addition, tourism demand is particularly sensitive to security and health concerns, and the industry is highly susceptible to changes in the international political situation, natural disasters, and epidemics (Mao et al. 2010). The hallmark event considered in this paper during the period 2001-2013 is the SARS epidemic, used as an exogenous dummy variable for external shock, D_SARS. The VAR model is as follows:

$$
\begin{aligned}
& \Delta \mathrm{USTA}_{\mathrm{t}}=\alpha_{1}+\sum_{i=1}^{m} \lambda_{1}(i) \Delta \mathrm{USTA}_{\mathrm{t}-\mathrm{i}}+\sum_{i=1}^{m} \beta_{1}(i) \Delta \mathrm{USPDI}_{\mathrm{t}-\mathrm{i}}+\sum_{i=1}^{m} \gamma_{1}(i) \Delta \mathrm{USCL}_{\mathrm{t}-\mathrm{i}} \\
& +\sum_{i=1}^{m} \delta_{1}(i) \Delta \mathrm{USSP}_{\mathrm{t}-\mathrm{i}}+a_{1} \mathrm{D} \_\mathrm{SARS}_{\mathrm{t}}+\varepsilon_{t 1} \\
& \Delta \mathrm{USPDI}_{\mathrm{t}}=\alpha_{2}+\sum_{i=1}^{m} \lambda_{2}(i) \Delta \mathrm{USTA}_{\mathrm{t}-\mathrm{i}}+\sum_{i=1}^{m} \beta_{2}(i) \Delta \mathrm{USPDI}_{\mathrm{t}-\mathrm{i}}+\sum_{i=1}^{m} \gamma_{2}(i) \Delta \mathrm{USCL}_{\mathrm{t}-\mathrm{i}} \\
& +\sum_{i=1}^{m} \delta_{2}(i) \Delta \mathrm{USSP}_{\mathrm{t}-\mathrm{i}}+a_{2} \mathrm{D}_{-} \mathrm{SARS}_{\mathrm{t}}+\varepsilon_{t 2} \\
& \Delta \mathrm{USCL}_{\mathrm{t}}=\alpha_{3}+\sum_{i=1}^{m} \lambda_{3}(i) \Delta \mathrm{USTA}_{\mathrm{t}-\mathrm{i}}+\sum_{i=1}^{m} \beta_{3}(i) \Delta \mathrm{USPDI}_{\mathrm{t}-\mathrm{i}}+\sum_{i=1}^{m} \gamma_{3}(i) \Delta \mathrm{USCL}_{\mathrm{t}-\mathrm{i}} \\
& +\sum_{i=1}^{m} \delta_{3}(i) \Delta \mathrm{USSP}_{\mathrm{t}-\mathrm{i}}+a_{3} \mathrm{D}_{-} \mathrm{SARS}_{\mathrm{t}}+\varepsilon_{t 3} \\
& \Delta \mathrm{USSP}_{\mathrm{t}}=\alpha_{4}+\sum_{i=1}^{m} \lambda_{4}(i) \Delta \mathrm{USTA}_{\mathrm{t}-\mathrm{i}}+\sum_{i=1}^{m} \beta_{4}(i) \Delta \mathrm{USPDI}_{\mathrm{t}-\mathrm{i}}+\sum_{i=1}^{m} \gamma_{4}(i) \Delta \mathrm{USCL}_{\mathrm{t}-\mathrm{i}} \\
& +\sum_{i=1}^{m} \delta_{4}(i) \Delta \mathrm{USSP}_{\mathrm{t}-\mathrm{i}}+a_{4} \mathrm{D}_{-} \mathrm{SARS}_{\mathrm{t}}+\varepsilon_{t 4}
\end{aligned}
$$

where the variables $\Delta \mathrm{USTA}, \Delta \mathrm{USPDI}, \Delta \mathrm{USCL}$, and $\Delta \mathrm{USSP}$ are stationary $(\Delta$, the first-difference operator), $\alpha$ is a constant, and the residual $\varepsilon$ is Gaussian white noise with zero mean and constant variance. $\lambda, \beta, \gamma, \delta$, a, and b are coefficients. 
The non-economic dummy variable D_SARS captures the influence of the oneoff event of the SARS outbreak in April 2003, which takes the value of 1 during the corresponding quarter on the event date and 0 otherwise. The number of lags is determined by AIC and likelihood ratio (LR) tests, by which the optimal lag is 4 , selected with the lowest value of the AIC criteria, and the null hypothesis in LR is rejected at the $1 \%$ significance level.

\subsection{Generalized impulse response analysis}

An impulse response function measures the time profile of the effect of shocks at a given point on the expected future values of variables for a dynamic system. This study uses the generalized impulse response function (Pesaran and Shin 1996) to analyze the short-run dynamics of the variables, because it has a unique solution and is invariant to the ordering of the variables in VAR, unlike orthogonalized impulse response. The dynamic response of the change of tourist arrivals (tourism demand) to innovations in the macroeconomic factors can be traced out by the generalized impulse response analysis. This approach enables us to see

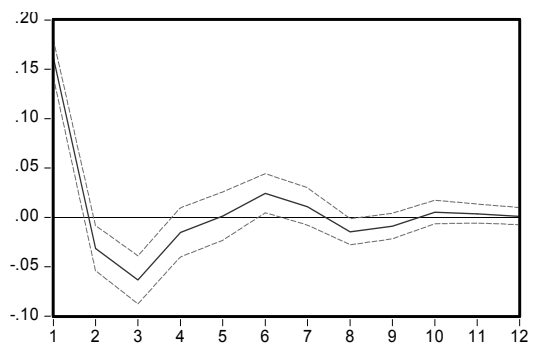

(a)Response of $\triangle$ USTA to $\triangle$ USTA

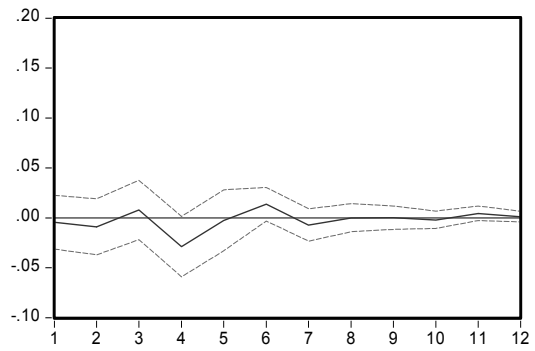

(c)Response of $\triangle \mathrm{USTA}$ to $\triangle \mathrm{USCL}$

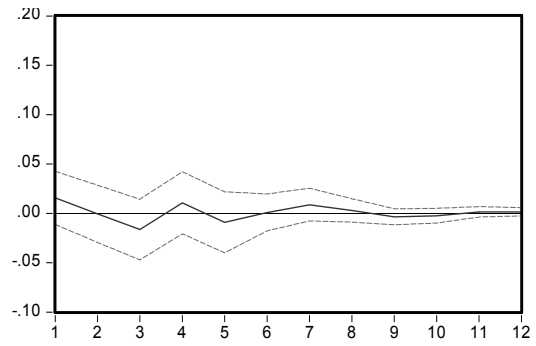

(b)Response of $\triangle$ USTA to $\triangle$ USPDI

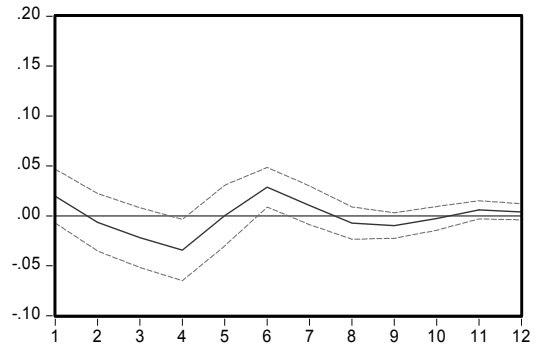

(d)Response of $\triangle$ USTA to $\triangle$ USSP

Figure 4. Generalized impulse response for the short run

Note: The response to generalized one S.D. innovation \pm 2 S.E. USTA, USPDI, USCL, and USSP mean tourist arrivals, US PDI, cost of living, and substitute price, respectively. 
the responses of the change of USTA ( $\triangle$ USTA) to the changes of itself, USPDI ( $\triangle \mathrm{USPDI}), \mathrm{USCL}(\triangle \mathrm{USCL})$, and USSP ( $\triangle \mathrm{USSP})$, as given in Figure 4.

Runkle (1987) proposed that impulse response functions with standard errors or confidence intervals are equivalent to regression coefficients with t-statistics. Doan and Litterman (1986) argued that confidence bands around the mean response can be used for statistical inference. The response is said to be significant at the $95 \%$ confidence level when the upper and lower bands show the same sign simultaneously (Chen and Kim 2010).

The responses of tourism demand to the shocks occurring in each variable over a 15-month period are plotted in Figure 4(a): a shock in the variable itself of the first-differenced tourist arrival ( $\triangle \mathrm{USTA}$ ) will have a relatively larger impact on the current level of the change of tourist arrivals, and, as in general, oscillation takes place along the time axis for the first-differenced data. This impact oscillation will gradually die off and disappear after 11 periods (months). This response is clearly significant at the $95 \%$ level, as the upper and lower bands exhibit the same sign.

In Figure 4(b), the response of the change of tourist arrivals ( $\triangle$ USTA) to a shock in the change of US PDI ( $\triangle$ USPDI) is positive at the beginning, which implies that the income elasticity of the tourism demand is positive, and this kind of tourism product belongs to normal goods. For short-run behaviours, oscillation follows within small amplitude and takes about eight periods to vanish. It seems that the influence of $\triangle \mathrm{USPDI}$ shock on $\triangle \mathrm{USTA}$ is not significant, according to the suggestion of Doan and Litterman (1986). This may contribute to the big gap between the two countries' national incomes, resulting in the US tourists not being sensitive to their PDI change.

The shock in the change to the cost of living ( $\triangle \mathrm{USCL}$ ) as shown in Figure $4(c)$ has a negative impact on tourism demand initially, which is consistent with the basic law of demand that as the price rises, the demand goes down. Although the momentum of the impact is small before dying off, at the sixth period, the lower band approaches the horizontal axis very closely, nearly satisfying the $95 \%$ confidence level. We deem that the influence of cost of living on tourist arrivals for the short run is significant. This impact oscillation takes about eight periods to disappear.

However, the response of the tourism demand change ( $\triangle$ USTA) to the shock in the substitute price change ( $\triangle$ USSP) in Figure $4(d)$ is immediately positive and significant, which implies that initially, the cross-elasticity is greater than zero; in other words, the tourism products of Taiwan and its opponent Hong Kong are regarded as substitutes. Similarly for the short-run analysis, oscillation comes up along the time axis and disappears after eleven periods. 


\section{CONCLUDING REMARKS}

The tourism industry can be another major contributing factor to Taiwan's economic growth. The 2011 annual statistics of the Tourism Bureau of Taiwan reported that Taiwan's tourism receipts had accounted for 5.98\% of the GDP. This figure exceeded the contribution of the agricultural sector to the GDP, thereby making tourism one of Taiwan's main industries. Not only does development in the tourism sector increase national income; it also diversifies the range of industries, and in particular, industrial diversity can reduce the risks associated with dependence on an export-oriented economy if an economic recession occurs. Therefore, tourism will play a very important role in Taiwan's future.

Tourism demand analysis is regarded as a necessity for tourism policy making. This empirical study aimed to understand how the important economic factors including PDI, the cost of living for tourists, and the substitute price affect the tourist arrivals from an individual origin country, namely, the US, by analysing monthly data from 2001 to 2013. In this data period, it was found that cointegration exists among the four model variables, and thus there exists a long-run relationship among the variables. With regard to the short-run analysis, the responses of the changes of the tourist arrivals to themselves, the cost of living, and the substitute price achieved the $95 \%$ confidence level. In addition, the result of the tourist arrivals initially responding to PDI implies that the income elasticity of tourism demand is positive, and further, this kind of tourism product belongs to normal goods. The initial response to the shock in the change of cost of living verifies the basic law of demand. Finally, the outcome of the tourist arrivals to the substitute price shows that the cross-elasticity is greater than zero; hence, the tourism products of Taiwan and its opponent Hong Kong are both substitute goods. Overall, the short-run equilibrium adjustment process was quite fast.

This study suggests that the Taiwanese government and tourism industry must pay more attention to these macroeconomic factors for short-run analyses to make policy decisions, especially regarding US tourists, since the US is a longtime, mature, but not a high growth market. Hong Kong must be regarded as the main competing destination for US tourists due to the significant influence of the substitute price change calculated by Hong Kong's CPI. In the future, we hope to compare different important source countries or regions, such as Japan, Hong Kong, South Korea, and Singapore, to obtain more detailed information for Taiwan's tourism industry. In addition, the Taiwanese government has formally opened the gates to tourists from mainland China since July 2008, which contributed to the fact that more than eight million international tourists visited Taiwan in 2013. Therefore, China will also be an important target for future research on this subject. 


\section{REFERENCES}

Ahmed, J. and Kwan, A.C.C. (1991). Causality between exports and economic growth: empirical evidence from Africa. Economics Letters, 37(3), 243-248.

Balaguer, J. and Cantavella-Jorda, M. (2002). Tourism as a long-run economic growth factor: the Spanish case. Applied Economics, 34(7), 877-884.

Bodie, Z., Alex, K. and Alan, M.J. (2001). Essentials of Investments (5 $5^{\text {th }}$ Ed.). McGraw-Hill, New York.

Brida, J.G., Risso, W.A., Lanzilotta, B., and Lionetti, S. (2010). The tourism-led-growth hypothesis for Uruguay. Tourism Economics, 16(3), 765-771.

Burger, C.J.S.C., Dohnal, M., Kathrada, M. and Law, R. (2001). A practitioner's guide to timeseries methods for tourism demand forecasting - a case study of Durban, South Africa. Tourism Management, 22(4), 403-409.

Chan, F., Lim, C. and McAleer, M. (2005). Modeling multivariate international tourism demand and volatility. Tourism Management, 26(3), 459-471.

Chang, I.Y. (2014). Critical success factors for international travel fairs, using the Taipei International Travel Fair as an example. Acta Oeconomica, 64(Supplement 2), 165-176.

Chao, C.C., Hazari, B.R., Laffargue, P. and Yu, S.H. (2009). A dynamic model of tourism, employment and welfare: the case of Hong Kong. Tourism Management, 14(2), 232-245.

Chen, C.F. and Song Zan, C.W. (2009). Tourism expansion, tourism uncertainty and economic growth: New evidence from Taiwan and Korea. Tourism Management, 30(6), 812-818.

Chen, M.H. and Kim, H.J. (2010). Tourism expansion and corporate earnings in the tourism industry. The Service Industries Journal, 30(6), 947-964.

Djeri, L., Armenski, T., Jovanović, T. and Dragin, A. (2014). How income influences the choice of tourism destination? Acta Oeconomica, 64(2), 219-237.

Doan, T. and Litterman, R. (1986). User's Manual RATS, Version 2.0. VAR Econometrics, Minneapolis.

Dritsakis, N. (2004). Cointegration analysis of German and British tourism demand for Greece. Tourism Management, 25(1), 111-119.

Engle, R.F. and Yoo, B.S. (1987). Foresting and testing in co-integrated systems. Journal of Econometrics, 35(1), 143-159.

Engle, R.F. and Granger, C.W.J. (1987). Co-integration and error correction: representation, estimation and testing. Econometrica, 55, 251-276.

Ghartey, E.E. (1993). Causal relationship between exports and economic growth: some empirical evidence in Taiwan, Japan and the US. Applied Economics, 25(9), 1145-1152.

Gunes, S. (2007). Functional income distribution in Turkey: a cointegration and VECM analysis. Journal of Economic and Social Research, 9(2), 23-26.

Hoffman, D.L. and Rasche, R.H. (1996). Assessing forecast performance in a cointegrated system. Journal of Applied Econometrics, 11(5), 495-517.

Katircioglu, S. (2009). Testing the tourism-led growth hypothesis: The case of Malta. Acta Oeconomica, 59(3), 331-343.

Kim, H.J., Chen, M.H. and Jang, S.C. (2006). Tourism expansion and economic development: the case of Taiwan. Tourism Management, 27(5), 925-933.

Kim, S. and Song, H. (1998). Analysis of inbound tourism demand in South Korea: a cointegration and error correction approach. Annals of Tourism Research, 3(1), 25-41.

Kulendran, N. and Witt, S.F. (2001). Cointegration versus least squares regression. Annals of Tourism Research, 28(2), 291-311. 
Lee, C.C. and Chien, M.S. (2008). Structure breaks, tourism development, and economic growth: Evidence from Taiwan. Mathematics and Computers in Simulation, 77(4), 358-368.

Lim, C. (1997). Review of international tourism demand models. Tourism Management, 24(4), $835-849$.

Lim, C. (2004). The major determinants of Korean outbound travel to Australia. Mathematics and Computers in Simulation, 64(3-4), 477-485.

Lim, C. and McAleer, M. (2001). Monthly seasonal variations, Asian tourism to Australia. Annals of Tourism Research, 28(1), 68-82.

Maghyereh, A. (2004). Oil price shocks and emerging stock markets: a generalized VAR approach. International Journal of Applied Econometrics and Quantitative Studies, 1(2), 27-40.

Mao, C.K., Ding, C.G. and Lee, H.Y. (2010). Post-SARS tourist arrival recovery patterns: An analysis based on a catastrophe theory. Tourism Management, 31(6), 855-861.

Marrocu, E. and Paci, R. (2013). Different tourists to different destinations. Evidence from spatial interaction models. Tourism Management, 39, 71-83.

Naka, A. and Tufte, D. (1997). Examining impulse response functions in cointegrated systems. Applied Economics, 29(12), 1593-1603.

Oh, C.O. (2005). The contribution of tourism development to economic growth in the Korea economy. Tourism Management, 26(1), 39-44.

Pesaran, M.H. and Shin, Y. (1996). Cointegration and the speed of convergence to equilibrium. Journal of Econometrics, 71(1-2), 117-143.

Qiu, H. and Zang, J. (1995). Determinants of tourist arrivals and expenditures in Canada. Journal of Travel Research, 34(2), 43-49.

Runkle, D.E. (1987). Vector auto regression and reality. Journal of Business and Economics Statistics, 5(1), 437-442.

Schubert, S.F., Brida, J.G. and Risso, W.A. (2011). The impacts of international tourism demand on economic growth of small economies dependent on tourism. Tourism Management, 32(2), $377-385$.

Song, H. and Witt, S.F. (2003). Tourism foresting: the general-to-specific approach. Journal of Travel Research, 42(1), 65-74.

Song, H. and Witt, S.F. (2006). Forecasting international tourist flows to Macau. Tourism Management, 27(2), 214-224.

Song, H., Romilly, P. and Liu, X. (2000). An empirical study of outbound tourism demand in the U.K. Applied Economics, 32(5), 611-624.

$\mathrm{Su}, \mathrm{Z}$. (2014). Why Chinese central bank should focus on headline inflation. Acta Oeconomica, 64(Supplement 2), 39-51.

Toda, B.H. and Yananoto, T. (1995). Statistical inference in vector auto regressions with possibly integrated processes. Journal of Econometrics, 66, 1(2), 225-250. 